\title{
Emission factors from road dust resuspension in a Mediterranean freeway
}

\author{
F. Amato \\ A. Karanasiou \\ T. Moreno \\ A. Alastuey \\ J.A.G. Orza' J. Lumbreras \\ R. Borge \\ E. Boldo \\ C. Linares \\ X. Querol
}

\begin{abstract}
A B S T R A C T
Particulate matter emissions from paved roads are currently one of the main challenges for a sustainable transport in Europe. Emissions are scarcely estimated due to the lack of knowledge about the resuspension process severely hampering a reliable simulation of PM and heavy metals concentrations in large cities and evaluation of population exposure. In this study the Emission Factors from road dust resuspension on a Mediterranean freeway were estimated per single vehicle category and PM component (OC, $\mathrm{EC}$, mineral dust and metals) by means of the deployment of vertical profiles of passive samplers and terminal concentration estimate. The estimated $\mathrm{PM}_{10}$ emission factors varied from 12 to $47 \mathrm{mg} \mathrm{VKT}^{-1}$ (VKT: Vehicle Kilometer Traveled) with an average value of $22.7 \pm 14.2 \mathrm{mg} \mathrm{VKT}^{-1}$. Emission Factors for heavy and light duty vehicles, passenger cars and motorbikes were estimated, based on average fleet composition and EPA ratios, in $187-733 \mathrm{mg} \mathrm{VKT}^{-1}, 33-131 \mathrm{VKT}^{-1}, 9.4-36.9 \mathrm{VKT}^{-1}$ and $0.8-3.3 \mathrm{VKT}^{-1}$, respectively. These range of values are lower than previous estimates in Mediterranean urban roads, probably due to the lower dust reservoir on freeways. PM emitted material was dominated by mineral dust $\left(9-10 \mathrm{mg} \mathrm{VKT}^{-1}\right)$, but also OC and EC were found to be major components and approximately 14 $-25 \%$ and $2-9 \%$ of average PM exhaust emissions from diesel passenger cars on highways respectively.
\end{abstract}

\section{Introduction}

Road dust resuspension is an important source of PM in cities (Thorpe et al., 2007; Amato et al., 2009a; II Position paper EC). The large contribution of this source to the mass of ambient air $\mathrm{PM}_{10}$ severely hampers the attainment of EU $\mathrm{PM}_{10}$ limit values in many urban environments (EEA, 2012; Harrison et al., 2008).
Furthermore, the unusual chemistry of many road dust particles is also relevant for their potential health risk: brake-tire-road abraded particles are embedded in the road dust reservoir and contain high concentrations of heavy metals such as $\mathrm{Fe}, \mathrm{Cu}, \mathrm{Zn}, \mathrm{Sb}, \mathrm{Ba}$ and other toxic elements (Cahill et al., 2011a, 2011b, Ostro et al., 2011; Gustafsson et al., 2008; Pengchai et al., 2004). The interest in road dust emissions is therefore likely to increase in the future, since no control measures strategies are currently taken to reduce such emissions whereas motor exhaust emission rates (primary PM and gaseous emission per single vehicle) have been successfully regulated in the last fifteen years. 
In spite of their major role in determining PM and heavy metals concentrations in cities, road dust emissions have not been exhaustively studied nor accounted by models for geographical analysis of air quality impact, health effects and remediation measures. Road dust emissions might be one of the main causes for the discrepancies between modeled and measured PM concentrations. Modelers suffer the lack of experimental studies needed for Emission Factors estimates (EF), which are the starting point for dispersion modeling. Other uncertainties on road dust are: i) the poor geographical coverage of available EF, as most studies report results for in Central Europe and Scandinavian Countries (Schaap et al., 2009) while emissions patterns at the Mediterranean region are different due to specific dry climate; ii) the classification of EFs based on vehicle categories is scarcely known; iii) the spatial (type of roads) and temporal variability of emission strength needs to be quantified; iv) EFs are rarely estimated for road dust components; v) the straightforward "EF $\times$ activity" approach might not be able to describe the complex phenomenon of resuspension, which is affected by many parameters: amount of dirtiness on the road, state of pavement, temperature, humidity, rainfall, climate, etc.

This study aims to estimate the vehicle-based Emission Factors from road dust PM and components (heavy metals, mineral dust, organic carbon (OC) and elemental carbon (EC)) at a freeway in Barcelona (Spain), a typical Mediterranean city which has infrequent precipitation and poor vegetative cover. In addition we discuss the suitability of expressing emissions as a function of active traffic area.

\section{Methods}

\subsection{Study site}

Barcelona is the second largest city in Spain with one of the highest car densities in Europe $\left(5.9\right.$ kcars $\left.\mathrm{km}^{-2}\right)$ and a Mediterranean dry climate with infrequent precipitations. Annual $\mathrm{PM}_{10}$ concentrations at the urban background are increased on average by $17 \%\left(7 \mu \mathrm{g} \mathrm{m}^{-3}\right.$ ) due to non-exhaust emissions (Amato et al., 2009a), and by $46 \%$ due to the total road traffic contribution. Being the regional contribution less than 30\% (Amato et al., 2009a), it derives that controlling local sources is very important for attaining $\mathrm{PM}_{10}$ limit values. Perez et al. (2008) estimated that $80 \%$ of daily exceedances of the $\mathrm{PM}_{10}$ daily limit value $\left(50 \mu \mathrm{g} \mathrm{m}^{-3}\right)$ are caused by anthropogenic mineral dust. The exposure scenario is even more problematic considering that $56 \%$ of urban population live less than $70 \mathrm{~m}$ away from major roads $\left(>10,000\right.$ vehicles day ${ }^{-1}$ ).

In this source-oriented study, field sampling was carried out along the B20, an extremely busy urban ring road surrounding the city center from South-West to North-East with the highest traffic intensity of the Metropolitan Area: 167,000 vehicles on a typical working day (Fig. 1). http://www.bcn.es/estadistica/catala/dades/ anuari/cap15/C1511020.htm. Each direction of the ring road has three lanes ( $9 \mathrm{~m}$ total width). In principle, access is prohibited to vehicles heavier than $3500 \mathrm{~kg}$, but our everyday experience suggests that a significant number of infractions of this rule occur daily. A traffic counter registers in fact $1.4 \%$ of vehicles longer than $7 \mathrm{~m}$. There are no traffic lights, crossings are made by bridging, tunnels or by covering completely some stretches of the B20. The study was carried out at three locations, two open-air (locations 4 and 5) in the right sidewalk of the North facing carriage, and one at a canyon location in the right sidewalk of the South facing carriage (location 7).

\subsection{Experimental approach}

Micro-scale vertical profiles of PM concentrations were investigated by means of the samplers utilized by Orza et al. (2009) for estimating horizontal aeolian sediment fluxes in erosion events. These samplers consist of five cylindrical canisters of $6 \mathrm{~cm}$ height and $7 \mathrm{~cm}$ of inner diameter. The five canisters are set in a vertical

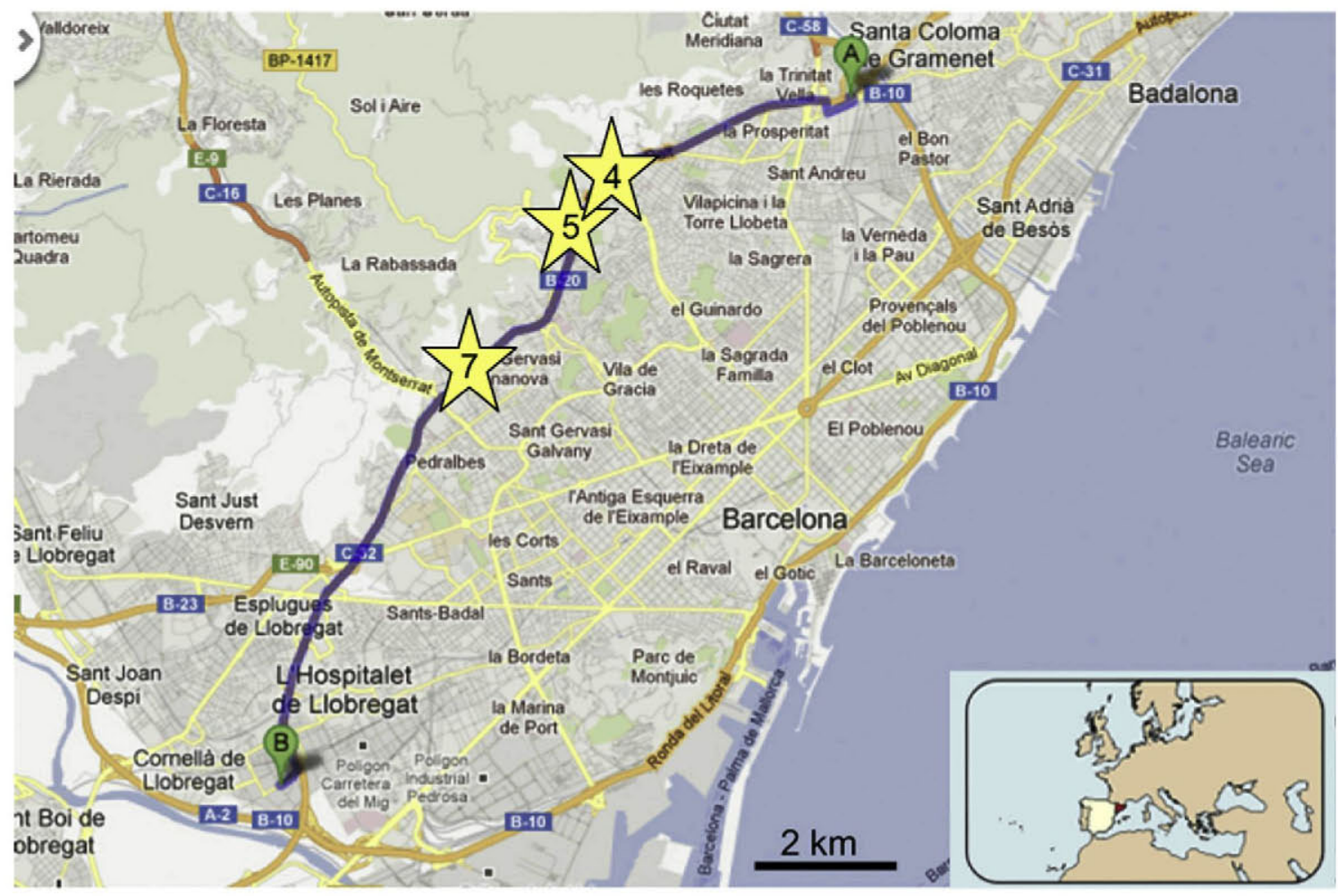

Fig. 1. Map of the city and locations (4,5 and 7) of the study. 
arrangement, separated by $1 \mathrm{~cm}$ each other. The canisters are crossed by a cylindrical steak that maintains the whole joined. Therefore, the open area of the canisters has a ring shape (Fig. 2).

Totally five arrays were used, divided into two experiments (A and $B$ ): the first experiment involved 2 arrays (at locations 4 and 7 ) of samplers and was conducted in May 2010 with a sampling time of $624 \mathrm{~h}$; the second experiment took place in July 2010, repeating the procedure but adding a third array at location 5, with a sampling time of $312 \mathrm{~h}$. Precipitation took place only during the first experiment, with 23 rainy hours (out of 624). After sampling, the canisters were brought to laboratory and the dust deposited in the canisters was recovered with water. This method although efficient has the obvious disadvantage of losing the water soluble species (salts, water soluble organics etc.). Therefore, this paper deals with the insoluble material emitted by resuspension. The water soluble mass fraction of road dust is however expected to be low: Amato et al. (2009b) found $<2 \%$ content of soluble inorganic species in road dust mass in Barcelona, elemental carbon in insoluble in water, and Ruellan and Cachier (2001) found only $12 \%$ soluble fraction of freshly emitted organic carbon. The mass of dust was determined gravimetrically after sieving the collected dust at $63 \mu \mathrm{m}\left(\mathrm{PM}_{63}\right)$ and filtering the resulting suspensions with a Büchner flask into quartz filters. For two arrays ( $4 \mathrm{~A}$ and $7 \mathrm{~B}$ ), a quarter of each filter was acid digested ( $5 \mathrm{ml} \mathrm{HF}, 2.5 \mathrm{ml} \mathrm{HNO}_{3}, 2.5 \mathrm{ml} \mathrm{HClO}_{4}$ ) for the determination of major and trace elements and analyzed respectively by inductively coupled plasma mass spectrometry and atomic emission spectrometry (ICP-MS and ICP-AES) (Querol et al., 2001). A fraction of $1.5 \mathrm{~cm}^{2}$ of the filter was used for the determination of $\mathrm{OC}$ and EC content by means of the thermo-optic analysis (Sunset analyzer). In every case, blank concentrations were subtracted for determining final concentrations.

The operation principle of the samplers is similar to that described by Vawda et al. (1990) or Wagner and Leith (2000). The samplers are simply exposed to ambient air for passive collection of PM by deposition. An array of three samplers permits obtaining the vertical profile of concentrations which is a consequence of two opposite transport directions. On the one hand, the particles descend at a constant rate, established by the deposition velocity. On the other hand, the turbulent eddies induce a rising movement of the particles.

The deposition flux can be calculated by the terminal concentration $m_{\infty}$ divided by the deposition area $A$, and the sampling time $t$ (h) (Wagner and Leith, 2000):

$J=\frac{m_{\infty}}{A \cdot t}$

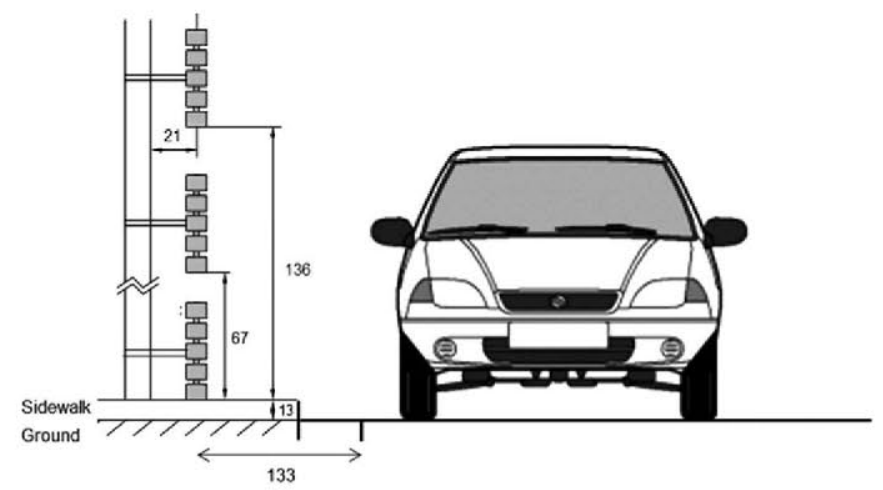

Fig. 2. Array of 3 samplers at one location. Distances (in $\mathrm{cm}$ ) and referred to location exit 4 (heights change slightly at other locations) where $m_{\infty}$ can be obtained by a least squares fit of the 15 canister concentrations to an equation of the form of

$\frac{m-m_{\infty}}{m_{0}-m_{\infty}}=\exp \left(-\frac{v_{\mathrm{d}}}{D}\right)$

where $v_{\mathrm{d}}$ is the deposition velocity, $D$ is an effective particle eddy diffusivity, $z$ is the height and $m_{0}$ and $m$ are the concentrations at height $z=0$ and $z=z^{\prime}$ respectively. The theoretical basis on which is based Equation (2) can be found in Escrig et al. (2011), which assumes that the dry deposition of particulate matter is governed by diffusion-like and gravitational-like mechanisms (Pasquill, 1962).

Once the net deposition flux is obtained, this can be converted to emission rate (Escrig et al., 2011) of road dust particle, which include also a portion of wear and exhaust particles that have previously deposited on the ground. Venkatram (2000) noted that if the road dust emissions depend on the amount of deposited dust in the road surface, then necessarily this dust loading has to evolve with time, until it is replenished at the same rate that it is removed. A simple mass balance helps to visualize this fact. Let $M$ be the mass of road dust per unit area at a time $t$, and $J$ the dust deposition flux. Supposing that the removal (i.e. emission flux) of road dust is a continuous process described by an unknown function of $M$, denoted by $f(M)$, the time evolution of $M$ must obey:

$\frac{\mathrm{d} M}{\mathrm{~d} t}=J-f(M)$

We will assume two additional hypotheses: (i) $J$ is constant in time, and (ii) $f(M)$ increases monotonically with $M$. Indeed, these hypotheses are often tacitly assumed.

Suppose that at a certain instant the value of $M$ is such that $f(M)<J$. Then, in the next (infinitely closer) instant, $M$ will increase and the same will happen with $f(M)$, and therefore the difference $J-f(M)$ will become smaller. In an infinite succession of such events, $f(M)$ will progressively augment as its magnitude is getting balanced with $J$, and $\mathrm{d} M / \mathrm{d} t$ approaches to zero. As a consequence, given a long enough time, an equilibrium value of $M$ will be reached.

This approach was previously followed by Nicholson (2001), who estimated the $\mathrm{PM}_{10}$ resuspension by traffic in the UK from the assessment of its deposition. Nicholson's (2001) estimates are utilized in the UK emissions inventory (Dore et al., 2003).

Several studies showed also the empirical evidence of this process (Amato et al., in press; Alley and Smith, 1981; Grottker, 1987). They monitored the time variation of $M$ after a runoff episode, observing the asymptotic increase to a maximum value, corresponding to the equilibrium point between deposition and resuspension of particles.

\section{Results and discussion}

The deposited $\mathrm{PM}_{63}$ mass measured at different heights are plotted for each array of samplers in Fig. 3 and were fitted to an equation of the form of Equation (2) by means of a least squares method.

The amount of deposited $\mathrm{PM}_{63}$ mass diminishes with height. The shape of this profile was considered to be derived from the opposite transport processes described in the previous section. Apart from the downwards deposition of PM, the traffic generates turbulence that results in an ascending flow of PM. Both mechanisms are of course transient. However, we will suppose that, on average, the system can be described by the previously introduced steady-state model Equation (2). 

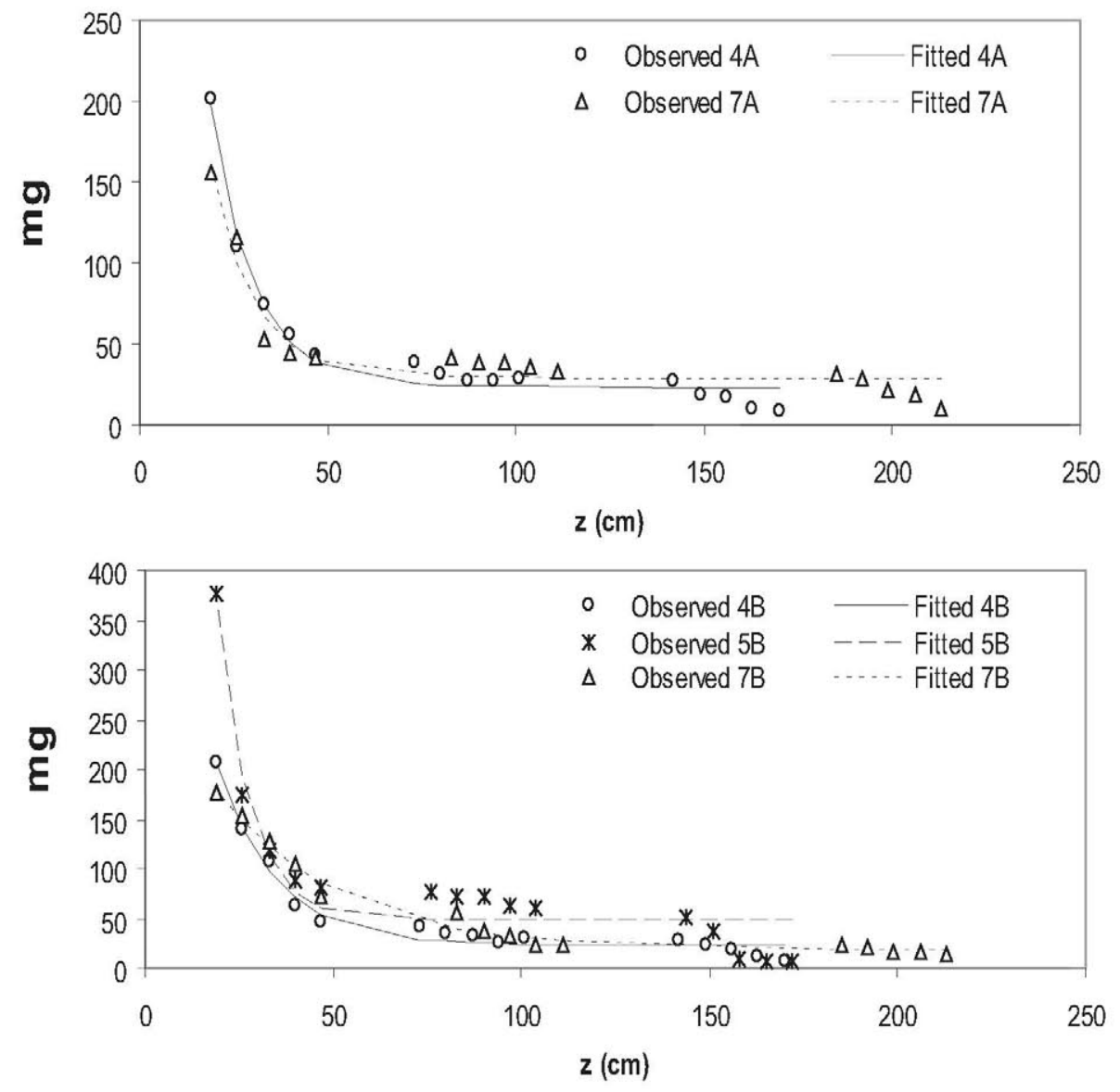

Fig. 3. Variation of the deposited $\mathrm{PM}_{63}$ mass with height.

As a result, a $m_{\infty}$ value was obtained. This value can be used for calculating the deposition flux onto the $z=0$ surface (Equation (1)).

The average terminal concentration $m_{\infty}$ establishes the total emissions from traffic resuspension during the whole period of passive collection. Based on a previous study under similar conditions in Spain (Escrig et al., 2011) where a constant size distribution of road dust was found, the fraction of particles $<10 \mu \mathrm{m}$ was assumed to be $40 \%$ of the collected $\mathrm{PM}_{63}$ (Fig. 4). The fitting parameters and the calculated $\mathrm{PM}_{10}$ emission factors for each of the five experiments are given in Table 1.

The estimated $\mathrm{PM}_{10}$ emission factors vary from 12 to $47 \mathrm{mg} \mathrm{VKT}^{-1}$ (VKT: Vehicle Kilometer Traveled) with an average value of $22.7+14.2 \mathrm{mg} \mathrm{VKT}^{-1}$. As expected, no clear difference was
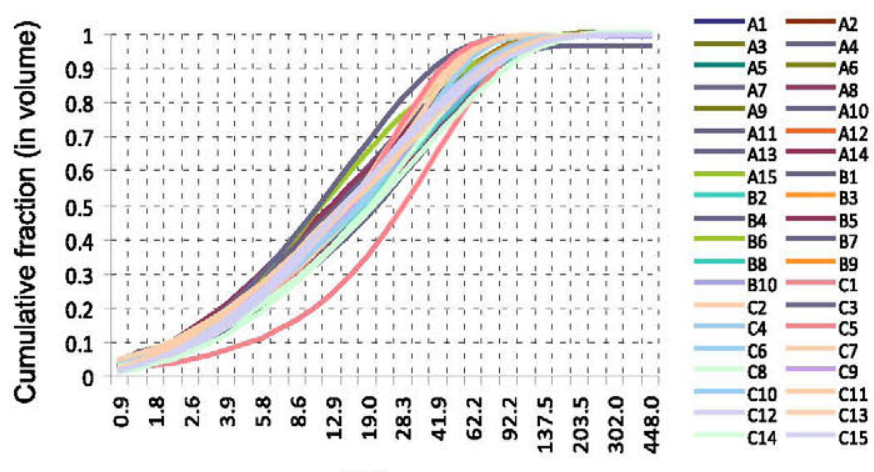

$\mu \mathrm{m}$

Fig. 4. Size distribution of PM collected at each canister by Escrig et al. (2011). observed between open-air and the canyon profile. This indicates that the input of external dust (not originated from the road itself) on the road surface was similar (i.e. no extra input at the open-air locations). These estimates must be intended as fleet-averaged. The composition of the fleet in Barcelona is typically: 63\% passenger cars, $31 \%$ motorcycles, $3.5 \%$ light duty vehicles and $2.5 \%$ heavy duty vehicles http://cbab.bcn.cat/uhtbin/cgisirsi/x/0/0/57/ 520/EST_8081?user_id=CATALA. Assuming this average fleet composition of Barcelona was representative of the freeway under study and that the ratios between EFs among different vehicle weight are those proposed by EPA (EPA, 2006, http://www.epa.gov/ $\mathrm{ttn} / \mathrm{chief} / \mathrm{ap} 42 / \mathrm{ch} 13 /$ index.html) we attempt to estimate EFs per single category of vehicles (Table 2 ).

While the second campaign did not register any precipitation, the EFs calculated for the first campaign (Experiments $4 \mathrm{~A}$ and $7 \mathrm{~A}$ ) might be slightly underestimated given that only the hours with rain were discounted whilst also during the hours immediately after rain, emissions are very low (Amato et al., in press). In any case, based on the limited literature available, the resuspension emission factor estimated in this study are in the range of reported emission factors for $\mathrm{PM}_{10}$ on freeways varying from $10 \mathrm{mg} \mathrm{VKT}^{-1}$ (Kupiainen et al., 2003) to $47 \mathrm{mg} \mathrm{VKT}^{-1}$ (Gehrig et al., 2004) and similar to the value used for motorways in the INFRAS emission factor handbook (INFRAS, 2004). These EF values are lower than those estimated at inner-city urban roads across Europe: Switzerland (17-92 mg VKT ${ }^{-1}$, only LDV), Germany (57-109 $\mathrm{mg} \mathrm{VKT}^{-1}$ ), Denmark (46-108 $\mathrm{mg} \mathrm{VKT}^{-1}$ ) Finland (121 $\mathrm{mg} \mathrm{VKT}^{-1}$ ) and Sweden (198 mg VKT $^{-1}$ ) (Gehrig et al., 2004; Ketzel et al., 2007). They are also lower than our previous study in the city center of 
Table 1

Fleet-averaged Emission Factors for $\mathrm{PM}_{10}$ and $\mathrm{PM}_{63}$ and fit parameters in the five experiments.

\begin{tabular}{|c|c|c|c|c|c|}
\hline & \multicolumn{2}{|c|}{ First campaign } & \multicolumn{3}{|c|}{ Second campaign } \\
\hline & $4 A$ & $7 \mathrm{~A}$ & $4 \mathrm{~B}$ & $7 \mathrm{~B}$ & $5 B$ \\
\hline$m_{0}(\mathrm{mg})$ & 941.5 & 743.9 & 637.5 & 305.4 & 2853.4 \\
\hline$m_{\infty}(\mathrm{mg})$ & 23.5 & 29.2 & 23.1 & 17.0 & 47.8 \\
\hline$v_{d} / D\left(\mathrm{~m}^{-1}\right)$ & 0.087 & 0.089 & 0.063 & 0.030 & 0.114 \\
\hline$R^{2}$ & 0.97 & 0.93 & 0.98 & 0.98 & 0.93 \\
\hline$J_{63}\left(\mathrm{mg} \mathrm{m}^{-2} \mathrm{~h}^{-1}\right)$ & 11.6 & 14.5 & 22.0 & 16.2 & 45.7 \\
\hline$J_{10}\left(\mathrm{mg} \mathrm{m}^{-2} \mathrm{~h}^{-1}\right)$ & 4.7 & 5.8 & 8.8 & 6.5 & 18.3 \\
\hline$E F_{63}\left(\mathrm{mg} \mathrm{VKT}^{-1}\right)$ & 30.0 & 37.4 & 56.8 & 41.8 & 117.8 \\
\hline $\mathrm{EF}_{10}\left(\mathrm{mg} \mathrm{VKT}^{-1}\right)$ & 12.0 & 14.9 & 22.7 & 16.7 & 47.1 \\
\hline
\end{tabular}

Barcelona where a fleet-averaged EF of $85 \mathrm{mg} \mathrm{VKT}^{-1}$ was found. In accordance with previous experimental studies measurements (Etyemezian. et al., 2003; Gehrig et al., 2004) motorway emission factors are expected to be lower than those of the other road types. Schaap et al. (2009) indicated that in the urban environment the resuspension per vehicle kilometer tends to be significantly higher than on motorways. The main differences are the higher average vehicle speeds and the higher traffic intensity on motorways, compared to urban roads, which both lead to a lower on-road dust reservoir. Also disturbed traffic flow due to traffic lights results in higher $\mathrm{PM}_{10}$ emissions (Lohmeyer et al., 2004; Gehrig et al., 2004; Thorpe et al., 2007). Moreover, in agreement with our results, the supply of dust from the surroundings of a motorway is likely to be significantly smaller than that of an urban road. Construction dust, urban unpaved parking areas and low-vegetated gardens (Amato et al., 2009a) are believed to be responsible for the extra supply of mineral dust at urban roads.

EFs for road dust components were calculated by the same approach described for PM. For each component two vertical profiles were obtained (Fig. 5), corresponding to samplings 4A and 7B. Table 3 shows the variation range of EFs for road dust components, which are intended as fleet-averaged, and compares them with previous studies. The main difference with previous studies is that we only account for the emissions due to resuspension (R), excluding the brake materials emitted directly to the atmosphere (DE).

For brake-related metals we assume that the fraction above $10 \mu \mathrm{m}$ is negligible with respect to total mass, as previously observed by Lough et al. (2005), Iijima et al. (2007) and Gietl et al. (2010). The EFs estimated in this study (0.029-0.031 $\mathrm{mgCu} \mathrm{VKT}^{-1}$ ) are much smaller than those found in the city center of Barcelona (0.48 $\mathrm{mgCu} \mathrm{VKT}^{-1}$, Amato et al., 2010), Oporto (0.26-0.40 $\mathrm{mgCu} \mathrm{VKT}^{-1}$, Oliveira et al., 2010) or Zurich (0.50 $\mathrm{mgCu} \mathrm{VKT}^{-1}$, Bukowiecki et al., 2009). As already mentioned, these studies estimated the total emission factors, accounting for direct emissions of brake-tire wear to the atmosphere plus the resuspension, whilst we estimated only the resuspension part. A similar finding was obtained by Bukowiecki et al. (2009) who estimated that road dust resuspension was responsible only for a fifth part of the total non-exhaust emissions of $\mathrm{Cu}$ in the city center of Zurich. Our comparison with the city center study in

Table 2

Emission Factors for $\mathrm{PM}_{10}$ per single category of vehicles.

\begin{tabular}{lrrrrrrr}
\hline $\mathrm{EF}_{10}\left(\mathrm{mg} \mathrm{VKT}^{-1}\right)$ & \multicolumn{3}{c}{ First campaign } & & \multicolumn{3}{c}{ Second campaign } \\
\cline { 2 - 3 } \cline { 7 - 8 } \cline { 7 - 8 } & \multicolumn{1}{c}{$4 \mathrm{~A}$} & \multicolumn{1}{c}{$7 \mathrm{~A}$} & & \multicolumn{1}{c}{ 4B } & \multicolumn{1}{c}{$7 \mathrm{~B}$} & \multicolumn{1}{c}{$5 \mathrm{~B}$} \\
\hline Passenger cars (PC) & 9.4 & & 17.8 & 13.1 & 36.9 \\
Heavy duty vehicles (HDV) & 186.9 & 232.6 & & 353.6 & 260.3 & 733.2 \\
Light duty vehicles (LDV) & 33.5 & 41.7 & & 63.4 & 46.7 & 131.5 \\
Motorbikes (MB) & 0.8 & 1.0 & & 1.6 & 1.2 & 3.3 \\
\hline
\end{tabular}

Barcelona (Amato et al., 2010) qualitatively shows that most of the brake-related emissions come from direct emissions, rather than due to resuspension. However, the metal emissions due to resuspension are still considerable and should be considered in Emission Inventories and Air Quality Plans.

In addition, the differences noted for $\mathrm{EF}_{\mathrm{PM}}$ between motorway and urban roads are hampered in the case of brake-related metals, due to the less frequency of braking. Bukowiecki et al. (2009) found that $\mathrm{EF}$ (direct emission + resuspension) of brake-related metals from roadway were smaller than city center conditions by one order of magnitude. Finally, also the unaccounted fraction of soluble materials in our study must be kept in mind (e.g. soluble antimony oxide).

For the Mineral Dust (MD in Fig. 5), we calculate EFs as the sum of Alumina, Silica, Calcium, Carbonate, Potassium, Titanium and Magnesium and assumed the same size distribution of PM (i.e. $40 \%$ of particles are $<10 \mu \mathrm{m})$. We did not find previous studies to compare our estimates with, but they account for approximately half $(44-54 \%)$ of the PM emissions due to resuspension, which is in agreement with Amato et al. (2011) who found that mineral sources contribute around $60 \%$ to road dust reservoir in Barcelona (whilst around $30 \%$ in Zurich).

OC and EC were also assumed to be distributed all within $0-10 \mu \mathrm{m}$. These represent respectively $7-14 \%$ and $5-6 \%$ of total road dust emissions. Amato et al. (2011) found that in average OC and EC constitute 11.7 and $3.0 \%$ of the mass of road dust. OC and EC emission factors due to road dust resuspension were compared to primary-OC and EC exhaust emission factors from passenger cars calculated within the EU TRANSPHORM project (Vouitsis et al., 2012). OC and EC fleet-averaged emissions due to resuspension in the freeway in Barcelona were much higher than the mean (averaging all types of EUROx and engine capacities) for exhaust gasoline-powered cars. The $\mathrm{OC}$ and EC emission factors found in this study were respectively, $14-25 \%$ and $2-9 \%$ of average diesel passenger cars on highways (Vouitsis et al., 2012).

\subsection{EF per unit of area}

Expressing the emission factor in mass per unit vehicle distance traveled implies the assumption that the deposition rate is directly proportional to the traffic flow rate. For the present case, it could be a realistic consideration because the high volume of traffic in the studied road is believed to produce high contributions to the road dust reservoir through wear (road surface, tires and brakes) and deposition of motor-exhaust particles. However, according to some authors it should not be taken as a general rule (Nicholson, 2001).

If emissions are in dynamic equilibrium with deposition, they can also be expressed in terms of active traffic area. This concept is not new. The VKT approach for estimating road dust emissions has been criticized by Nicholson (2001). His main concern relies on the fact that expressing EFs per vehicle and $\mathrm{km}$ traveled is a reliable approach in case of unpaved roads, where the available dust is inexhaustible, whilst the same is not true on paved roads. Nicholson and Branson (1990) and Nicholson et al. (1989) showed that a significant fraction of road dust could be removed from a given part of a paved road after the passage of a single vehicle. According to this, the total emission does not depend on the number of vehicles, but on the area of pavement traveled by vehicles and the time spanned.

Also according to Nicholson (2001) deposition does not depend on traffic intensity, "unless, the input of material on to the road surface is directly related to traffic density". In other words, the VKT approach is only valid if the ratio Deposition/Volume of vehicles is constant (i.e. the road dust is replenished almost exclusively by traveling vehicles). This is the case for example in construction 
- Obsened 4A Fitted 4A $\triangle$ Observed 7B Fitted 7B
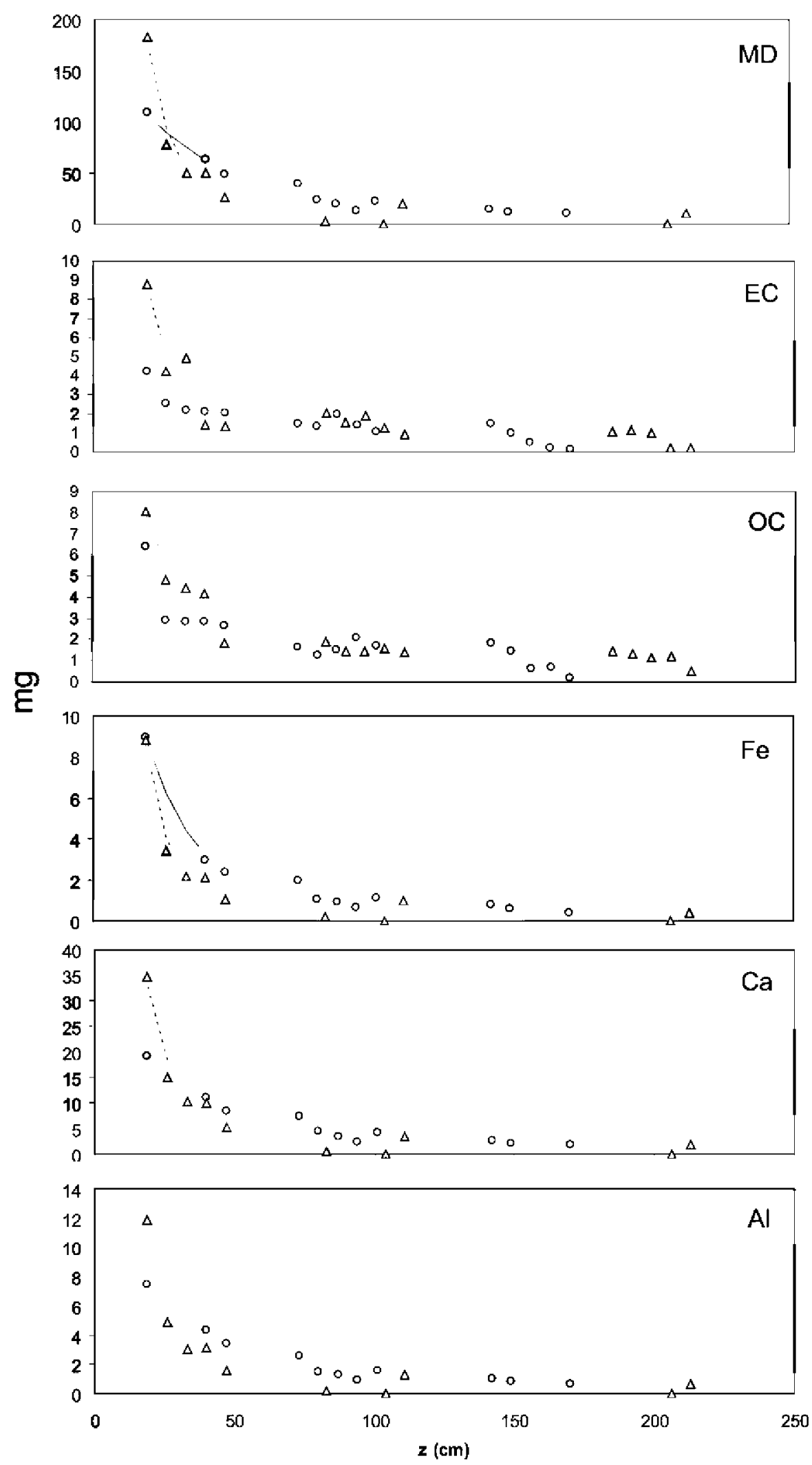

Fig. 5. Vertical profiles of major road dust components (mass $<63 \mu \mathrm{m}$ ). Height on $x$ axis. MD: mineral dust. 
Table 3

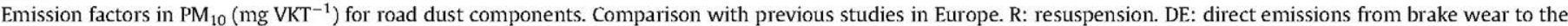
atmosphere.

\begin{tabular}{|c|c|c|c|c|c|c|c|c|}
\hline Emission sources & $\mathrm{R}$ & $\mathrm{DE}+\mathrm{R}$ & $\mathrm{DE}+\mathrm{R}$ & $\mathrm{DE}+\mathrm{R}$ & $\mathrm{DE}+\mathrm{R}$ & $\mathrm{DE}+\mathrm{R}$ & $\mathrm{DE}+\mathrm{R}$ & $\mathrm{DE}+\mathrm{R}$ \\
\hline Type of road & Freeway & Freeway $^{a}$ & Tunnel & Tunnel & Urban road & Urban road & Urban road & Urban road \\
\hline Reference & This study & $\begin{array}{l}\text { Bukowiecki } \\
\text { et al. (2009) }\end{array}$ & $\begin{array}{l}\text { Handler } \\
\text { et al. (2008) }\end{array}$ & $\begin{array}{l}\text { Sternbeck } \\
\text { et al. (2002) }\end{array}$ & $\begin{array}{l}\text { Bukowiecki } \\
\text { et al. (2009) }\end{array}$ & $\begin{array}{l}\text { Amato } \\
\text { et al. (2010) }\end{array}$ & $\begin{array}{l}\text { Oliveira } \\
\text { et al. }(2010)\end{array}$ & $\begin{array}{l}\text { Johansson } \\
\text { et al. (2009) }\end{array}$ \\
\hline Location & $\begin{array}{l}\text { Barcelona } \\
\text { (Spain) }\end{array}$ & $\begin{array}{l}\text { Reiden } \\
\text { (Switzerland) }\end{array}$ & $\begin{array}{l}\text { Vienna } \\
\text { (Austria) }\end{array}$ & (Sweden) & $\begin{array}{l}\text { Zurich } \\
\text { (Switzerland) }\end{array}$ & $\begin{array}{l}\text { Barcelona } \\
\text { (Spain) }\end{array}$ & $\begin{array}{l}\text { Oporto } \\
\text { (Portugal) }\end{array}$ & $\begin{array}{l}\text { Stockholm } \\
\text { (Sweden) }\end{array}$ \\
\hline \multicolumn{9}{|l|}{$\mathrm{mg} \mathrm{VKT}^{-1}$} \\
\hline $\begin{array}{l}\text { Mineral dust } \\
\text { (excl. iron) }\end{array}$ & $5.3-9.1$ & - & $21.2 \pm 9.5$ & - & - & - & - & - \\
\hline $\mathrm{Al}$ & $0.34-0.62$ & - & $1.4 \pm 0.7$ & - & - & - & - & - \\
\hline $\mathrm{Ca}$ & $0.98-1.64$ & - & $2.1 \pm 1.2$ & - & - & - & - & - \\
\hline$O C$ & $1.7-3.1$ & - & $18.8 \pm 3.5$ & - & - & - & - & - \\
\hline $\mathrm{EC}$ & $0.6-2.7$ & - & $21.3 \pm 3.4$ & - & - & - & - & - \\
\hline $\mathrm{Fe}$ & $0.99-1.17$ & 0.9 & $3.4 \pm 0.7$ & - & 8 & 7.4 & - & - \\
\hline \multicolumn{9}{|l|}{$\mu \mathrm{g} \mathrm{VKT}^{-1}$} \\
\hline $\mathrm{Cu}$ & $29-31$ & 50 & $156 \pm 34$ & $147-172$ & 500 & 480 & $260-400$ & 540 \\
\hline $\mathrm{Sb}$ & $1.4-2.1$ & 7 & $100 \pm 30$ & $32-51$ & 80 & 86 & - & 140 \\
\hline $\mathrm{Ba}$ & $19-36$ & 20 & $50 \pm 10$ & $136-293$ & 150 & - & - & - \\
\hline $\mathrm{Pb}$ & $16-22$ & - & $17 \pm 5$ & $35-37$ & - & - & - & 41 \\
\hline $\mathrm{Zn}$ & $39-61$ & - & $160 \pm 40$ & $205-239$ & - & - & - & 260 \\
\hline As & $0.2-0.3$ & - & - & - & - & - & - & - \\
\hline $\mathrm{Ni}$ & $1.3-1.4$ & - & - & - & - & - & - & 6 \\
\hline $\mathrm{Zr}$ & $0.3-0.5$ & 5 & - & - & 60 & - & $15-47$ & - \\
\hline Sn & $0.3-0.4$ & 6 & $25 \pm 18$ & - & 80 & 106 & - & 126 \\
\hline Mo & $0.068-0.70$ & 4 & - & - & 60 & - & - & 22 \\
\hline $\mathrm{Mn}$ & $16-23$ & - & $42 \pm 13$ & - & - & - & - & 11 \\
\hline
\end{tabular}

a Approximate values taken by charts.

works and industrial roads where the main source of road dust is the material lost by trucks. More generally at all those sites where a large fraction of road dust reservoir originates from traffic activities.

\section{Conclusions}

Road dust emission factors (EFs) from a Mediterranean freeway (Barcelona, Spain) were estimated from vertical profiles of PM mass concentrations collected passively next to the road and using the terminal concentration to calculate deposition and emission fluxes. Fleet-averaged EFs were found to vary within 12-47 $\mathrm{mgPM}_{10} \mathrm{VKT}^{-1}$, these being significantly lower than those found in the city centers but in the same range of other freeway studies in Central Europe.

Assuming that the average fleet composition of Barcelona was representative for the freeway under study and that the relative proportion between different vehicle-type emission factors are those proposed by AP-42 EPA, we estimated $\mathrm{EF}_{\mathrm{HDV}}, \mathrm{EF}_{\mathrm{LDV}}, \mathrm{EF}_{\mathrm{PC}}$ and $\mathrm{EF}_{\mathrm{MB}}$ in $187-733 \mathrm{mg} \mathrm{VKT}^{-1}, 33-131 \mathrm{VKT}^{-1}, 9.4-36.9 \mathrm{VKT}^{-1}$ and $0.8-3.3 \mathrm{VKT}^{-1}$, respectively.

The chemical characterization of resuspended PM revealed agreement with that of road dust particles collected in previous studies in Barcelona. Brake related metals show very low EFs when compared with central urban studies. This is due to two main reasons: i) at central urban sites EFs estimates included direct emissions from brake wear which are expected to dominate metal emissions; ii) a bigger reservoir of deposited metals is available in the city centers due to the higher braking frequency. Finally, resuspended mineral dust, $\mathrm{OC}$ and $\mathrm{EC}$ were revealed to be emitted in $9-10,1.7-3.1$ and $0.6-2.7 \mathrm{mg} \mathrm{VKT}^{-1}$ respectively. These are the first EF estimates available in Europe for these components.

\section{Acknowledgments}

This work was funded by research projects from the Spanish Ministries of the Environment and Rural and Marine Affairs
(SERCA-058/PC08/3-18.1) and Sciences and Innovation (GRACCIECSD2007-00067, VAMOSCGL2010-19464/CLI) and partly by research projects from the Dutch Ministry of Infrastructure and environment and a Post-Doctoral grant from the Spanish Ministry of Education (Ayudas para movilidad posdoctoral en centros extranjeros, Programa Nacional de Movilidad de Recursos Humanos del Plan Nacional de I-D+I 2008-2011).

\section{References}

Alley, W.M., Smith, P.E., 1981. Estimation of accumulation parameters for urban runoff quality modelling. Water Resources Research 17, 1657-1664.

Amato, F., Pandolfi, M., Escrig, A., Querol, X., Alastuey, A., Pey, J., Perez, N. Hopke, P.K., 2009a. Quantifying road dust resuspension in urban environment by Multilinear Engine: a comparison with PMF2. Atmospheric Environment 43 (17), 2770-2780.

Amato, F., Pandolfi, M., Viana, M., Querol, X., Alastuey, A., Moreno, T., 2009b. Spatial and chemical patterns of $\mathrm{PM}_{10}$ in road dust deposited in urban environment. Atmospheric Environment 43 (9), 1650-1659.

Amato, F., Nava, S., Lucarelli, F., Querol, X., Alastuey, A., 2010. A comprehensive assessment of PM emissions from paved roads: real-world emission factors and intense street cleaning trials. Science of the Total Environment 408 (20), 4309-4318.

Amato, F., Pandolfi, M., Moreno, T., Furger, M., Pey, J., Bukowiecki, N., Prevot, A., Baltensperger, U., Alastuey, A., Querol, X., 2011. Sources and variability of inhalable road dust particles in three European cities. Atmospheric Environment 45 (37), 6777-6787.

Amato, F., Schaap, M., Denier van der Gon, H.A.C., Pandolfi, M., Alastuey, A., Keuken, M., Querol, X. The effect of rain events on the mobility of the road dust load in two Dutch and Spanish roads. Atmospheric Environment, in press.

Bukowiecki, N., Lienemann, P., Hill, M., Figi, R., Richard, A., Furger, M., Rickers, K, Falkenberg, G., Zhao, Y., Cliff, S.S., Prevot, A.S.H., Baltensperger, U. Buchmann, B., Gehrig, R., 2009. Real-world emission factors for antimony and other brake wear related trace elements: size-segregated values for light and heavy duty vehicles. Environmental Science and Technology 43 (21), 8072-8078.

Cahill, T.A., Barnes, D.E., Withycombe, E., Watnik, M., 2011. Very fine and ultrafine metals and ischemic heart disease in the California Central Valley 2: 1974-1991. Aerosol Science and Technology 45 (9), 1135-1142.

Cahill, T.A., Barnes, D.E., Spada, N.J., Lawton, J.A., Cahill, T.M., 2011. Very fine and ultrafine metals and ischemic heart disease in the California central valley 1 : 2003-2007. Aerosol Science and Technology 45 (9), 1123-1134.

Dore, C.J., Goodwin, J.W.L., Watterson, J.D., Murrells, T.P., Passant, N.R. Hobson, M.M., Haigh, K.E., Baggott, S.L., Pye, S.T., Coleman, P.J., King, K.R., 2003. 
UK Emissions of Air Pollutants 1970 to 2001. Department of the Environment, Transport and the Regions, UK.

EC, April 2004. Second Position Paper on Particulate Matter-CAFE Working Group on Particulate Matter.

EEA, 2012. Exceedance of Air Quality Limit Values in Urban Areas (CSI 004) Assessment Published May 2012. http://themes.eea.europa.eu/IMS/ISpecs/ ISpecification20080701123452/IAssessment1243521792257/view_content.

EPA, 2006. AP-42. Compilation of Air Pollutant Emission Factors. fifth ed. U.S. Environmental Protection Agency, Research Triangle Park, NC. Fugitive Dust Sources (Chapter 13.2).

Escrig, A., Amato, F., Pandolfi, M., Monfort, E., Querol, X., Celades, I., Sanfélix, V. Orza, J.A.G., 2011. Simple estimates of vehicle-induced resuspension rates. Journal of Environmental Management 92 (10), 2855-2859.

Etyemezian, V., Kuhns, H., Gillies, J., Chow, J., Hendrickson, K., McGown, M., Pitchford, M., 2003. Vehicle-based road dust emission measurement - part III: effect of speed, traffic volume, location, and season on $\mathrm{PM}_{10}$ road dust emissions in the Treasure Valley, ID. Atmospheric Environment 37, 4583-4593. http://dx.doi.org/10.1016/S1352-2310(03)00530-2.

Gehrig, R., Hill, M., Buchmann, B., Imhof, D., Weingarter, E., Baltensprenger, U., 2004 Separate determination of $\mathrm{PM}_{10}$ emission factors of road traffic for tailpipe emissions and emissions form abrasion and resuspension processes. International Journal for Environment and Pollution 22, 312-332.

Gietl, J.K., Lawrence, R., Thorpe, A.J., Harrison, R.M., 2010. Identification of brake wear particles and derivation of a quantitative tracer for brake dust at a major road. Atmospheric Environment 44 (2), 141-146.

Grottker, M., 1987. Runoff quality from a street with medium traffic loading. Science of the Total Environment 59, 457-466.

Gustafsson, M., Blomqvist, G., Gudmundsson, A., Dahl, A., Swietlicki, E., Bohgard, M., Lindbom, J., Ljungman, A., 2008. Properties and toxicological effects of particles from the interaction between tyres, road pavement and winter traction material. Science of the Total Environment 393 (2-3), 226-240.

Handler, M., Puls, C., Zbiral, J., Marr, I., Puxbaum, H., Limbeck, A., 2008. Size and composition of particulate emissions from motor vehicles in the KaisermühlenTunnel, Vienna. Atmospheric Environment 42 (9), 2173-2186.

Harrison, R.H., Stedman, J., Derwent, D., 2008. New directions: why are $\mathrm{PM}_{10}$ concentrations in Europe not falling?. Atmospheric science perspectives specia series. Atmospheric Environment 42, 603-606.

Iijima, A., Sato, K., Yano, K., Tago, H., Kato, M., Kimura, H., Furuta, N., 2007. Particle size and composition distribution análysis of automotive brake abrasion dusts for the evaluation of antimony sources of airborne particulate matter. Atmospheric Environment 41 (23), 4908-4919.

INFRAS, 2004. HBEFA Handbuch Emissionsfaktoren des Strassenverkehrs. Version 2.1. INFRAS, UBA Berlin, UBA Wien, BUWAL.

Johansson, C., Norman, M., Burman, L., 2009. Road traffic emission factors for heavy metals. Atmospheric Environment 43 (31), 4681-4688.

Ketzel, M., Omstedt, G., Johansson, C., Düring, I., Pohjola, M., Oettl, D., Gidhagen, J. Wåhlin, P., Lohmeyer, A., Haakana, M., Berkowicz, R., 2007. Estimation and validation of $\mathrm{PM}_{2.5} / \mathrm{PM}_{10}$ exhaust and non-exhaust emission factors for practical street pollution modeling. Atmospheric Environment 41, 9370-9385. http:// dx.doi.org/10.1016/j.atmosenv.2007.09.005.

Kupiainen, K., Tervahattu, H., Räisänen, M., 2003. Experimental studies about the impact of traction sand on urban road dust composition. The Science of the Total Environment 308, 175-184.

Lohmeyer, A., Bachlin, W., During, I., 2004. Modelling of Vehicle Induced Nonexhaust $\mathrm{PM}_{10}$ Emissions. Paper Presented at PM and Emission Inventories Scientific Workshop, Milan, Italy, 18 October.
Lough, G.C., Schauer, J.J., Park, J.S., Shafer, M.M., Deminter, J.T., Weinstein, J.P., 2005. Emissions of metals associated with motor vehicle roadways. Environmental Science \& Technology 39, 826-836.

Nicholson, K.W., Branson, J.R., 1990. Factors affecting resuspension by road traffic. Science of the Total Environment 93, 349-358.

Nicholson, K.W., Branson, J.R., Giess, P., Cannell, R.J., 1989. The effects of vehicle activity on particle resuspension. Journal of Aerosol Science 20,1425-1428.

Nicholson, K.W., 2001. A critique of empirical emission factor models: a case study of the AP-42 model for estimating $\mathrm{PM}_{10}$ emissions from paved roads (Venkatram, A. Atmospheric Environment 34, 1\}11). Atmospheric Environment 35, 185-186.

Oliveira, C., Pio, C., Caseiro, A., Santos, P., Nunes, T., Mao, H., Luahana, L., Sokhi, R., 2010. Road traffic impact on urban atmospheric aerosol loading at Oporto, Portugal. Atmos Environ 44 (26), 3147-3158.

Orza, J.A.G., Cabello, M., Lidón, V., Martínez, J., 2009. Simple passive methods for the assessment of the directional and vertical distributions of wind-blown particulates. In: Advances in Studies on Desertification, Int. Conf. of Desertification in Memory of Professor John B. Thornes, 16-18 September 2009, Murcia, Spain, pp. 367-370.

Ostro, B., Tobias, A., Querol, X., Alastuey, A., Amato, F., Pey, J., Perez, N., Sunyer, J., 2011. The effects of particulate matter sources on daily mortality: a casecrossover study of Barcelona, Spain. Environmental Health Perspectives 119 (12), 1781-1787.

Pasquill, F., 1962. Atmospheric Diffusion. D. Van Nostrand, Princeton, NJ

Pengchai, P., Furumai, H., Nakajima, F., 2004. Source apportionment of polycyclic aromatic hydrocarbons in road dust in Tokyo. Polycyclic Aromatic Compounds $24(4-5), 773-789$

Perez, N., Pey, J., Querol, X., Alastuey, A., Lopez, J.M., Viana, M., 2008. Partitioning of major and trace components in $\mathrm{PM}_{10}, \mathrm{PM}_{2.5}$ and $\mathrm{PM}_{1}$ at an urban site in Southern Europe. Atmospheric Environment 42, 1677-1691.

Querol, X., Alastuey, A., Rodríguez, S., Plana, F., Mantilla, E., Ruiz, C.R., 2001. Monitoring of $\mathrm{PM}_{10}$ and $\mathrm{PM}_{2.5}$ around primary particulate anthropogenic emission sources. Atmospheric Environment 35, 845-858.

Ruellan, S., Cachier, H., 2001. Characterisation of fresh particulate vehicular exhausts near a Paris high flow road. Atmospheric Environment 35 (2), 453-468.

Schaap, M., Manders, A.M.M., Hendriks, E.C.J., Cnossen, J.M., Segers, A.J.S., Denier van der, Gon H.A.C., Jozwicka, M., Sauter, F.J., Velders, G.J.M., Matthijsen, J., Builtjes, P.J.H., 2009. Regional Modelling of Particulate Matter for the Netherlands. See: www.pbl.nl.

Stermbeck, J., Sjödin, A., Andreasson, K., 2002. Metal emissions from road traffic and the influence of resuspension - results from two tunnel studies. Atmospheric Environment 36, 4735-4744.

Thorpe, A., Harrison, R.M., Boulter, P.G., McCrae, I.S., 2007. Estimation of particle resuspension source strength on a major London Road. Atmospheric Environment 41, 8007-8020. http://dx.doi.org/10.1016/j.atmosenv.2007.07.006

Vawda, Y., Harrison, R.M., Nicholson, K.W., Colbeck, I., 1990. Use of surrogate surfaces for dry deposition measurements. Journal of Aerosol Science 21, S201-S204.

Venkatram, A., 2000. A critique of empirical emission factor models: a case study of the AP-42 model for estimating $\mathrm{PM}_{10}$ emissions from paved roads. Atmospheric Environment 34, 1-11.

Vouitsis, I., Ntziachristos, L., Samaras, Z., March 2012. "TRANSPHORM (Transport Related Air Pollution and Health Impacts - Integrated Methodologies for Assessing Particulate Matter) Deliverable D1.1.2: Methodology for the Quantification of Road Transport PM-emissions, Using Emission Factors or Profiles. Thessaloniki.

Wagner, J., Leith, D., 2000. Passive aerosol sampler. I: Principle of operation. Aerosol Science and Technology 34, 186-192. 